\title{
FISH DIGENEANS FROM THE SEVEN ISLANDS ORNITHOLOGICAL RESERVE AT OŚWIN LAKE. \\ PART II. THE EYEFLUKES-DIPLOSTOMUM SPP. AND TYLODELPHYS CLAVATA (VON NORDMANN, 1832)
}

\author{
Katarzyna MIERZEJEWSKA ${ }^{1 *}$, Teresa WEASOW $^{2}$ \\ ${ }^{1}$ Division of Fish Biology and Pisciculture, ${ }^{2}$ Division of Ichthyology \\ University of Warmia and Mazury in Olsztyn, Poland
}

\begin{abstract}
Mierzejewska K., Własow T., 2005. Fish digeneans from the Seven Islands ornithological reserve at Oświn Lake. Part II. The eyeflukes—Diplostomum spp. and Tylodelphys clavata (von Nordmann, 1832). Acta Ichthyol. Piscat. 35 (1): 1-5.
\end{abstract}

\begin{abstract}
Background. A parasitological survey was carried out in a shallow, eutrophic Oświn Lake (north-eastern Poland), within the Seven Islands ornithological reserve. We intended to compare the occurrence of eyeflukes in fish from two, distinctly demarcated pools of the lake, differing in environmental conditions. The effect of fish size and sampling season on the infection parameters was analysed and the present state of the parasite faunas was compared to the literature data. Material and methods. Within 1998 and 1999, a total of 1091 fishes representing 8 dominant species was examined. Samples were collected four times a year (in May, July, August, and October) simultaneously from the eastern- and western parts of the lake.

Results. Diplostomum spp. occurred in all the fish examined, numerously in roach, rudd, white bream, and carp bream. The parasite was less abundant in northern pike, crucian carp, and European perch. Tylodelphys clavata was found in roach and it sporadically occurred in northern pike, rudd, white bream, carp bream, and European perch. The infection rates of rudd and white bream in the eastern part of the lake were significantly higher than the respective values from the western part. The infection with both eyeflukes did not correlate with the fish length. The infection of roach, rudd, white bream, and carp bream with Diplostomum spp. and roach with $T$. clavata varied significantly in different experimental periods.

Conclusion. The eyeflukes as well as P. cuticola were sensitive indicators, reflecting the environmental pressure-both, spatial differences in ecological conditions within the same water body and long-term alterations. Diplostomum spp. did not accumulate with the age of fish. No seasonality was found for Diplostomum spp. or Tylodelphys clavata. Locationdependent occurrence of Diplostomum spp. in rudd and white bream indicated a limited fish interchange between the two pools of the lake.
\end{abstract}

Key words: parasites, fish, digeneans, Diplostomum spp., Tylodelphys clavata, Oświn Lake, Seven Islands reserve, Poland

\section{INTRODUCTION}

The study area was the eutrophic, pond-type Oświn Lake (mean depth $1.7 \mathrm{~m}$, surface area $890 \mathrm{ha}$ ). The Seven Islands bird sanctuary, located on the lake, has been under protection imposed by the Ramsar Convention since 1983 as a wetland of international importance, a breeding area of birds and their habitat. Oświn Lake underwent accelerated eutrophication in the 1970s. Rapid water level decrease and intoxication with chemical fertilizers all had lead to an ecological disaster by 1983 (Bryliński et al. unpublished). The water level was raised by a dam constructed on the Oświnka River (Mierzejewska et al. 2004), which halted the degradation process (Wiśniewski unpub- lished). After the occurrence of selective factors such as mass fish kills or the extinction of benthic fauna community (Bryliński et al. unpublished), it was interesting to investigate the current rate of fish infection with parasites in Oświn Lake.

The lake area consists of two pools separated by a shoal. The environmental conditions of the two pools are different. Current microbiological investigation indicated that the eastern pool is more fertile then the western one (Własow et al. 2003). The sedimentation dynamics in individual basins are different. The bottom of the eastern pool, in contrast to the western one, is completely covered with hornwort, Ceratophyllum demersum. On the other

\footnotetext{
* Correspondence: Dr Katarzyna Mierzejewska, Katedra Biologii i Hodowli Ryb, Uniwersytet Warmińsko-Mazurski w Olsztynie, ul. Oczapowskiego 5, 10-950 Olsztyn, Poland, phone/fax: (+4589) 523-3290, e-mail: katarzyna.mierzejewska@uwm.edu.pl
} 
hand, the shores of the western pool are overgrown with more trees and shrubs than the shores of the eastern basin.

Depending upon the respective conditions of particular pools different fish parasites find more- or less suitable conditions for their population growth. Due to their complex live cycles, which involves a variety of ecosystem components, digeneans seem to be sensitive component of parasite community which reflects environmental pressure (Valtonen and Gibson 1997, Halmetoja et al. 2000, Valtonen et al. 2003).

Posthodiplostomum cuticola matures in herons (Ardeidae) recognized as the characteristic parasite of fish in the lake studied (Kozicka 1963, Grabda and Grabda unpublished) was analysed in the first part of this work (Mierzejewska et al. 2004). Nevertheless herons are not observed at the area of Oświn Lake (Melin personal communication) the parasite remains the characteristic component of fish parasite community in the reservoir (Mierzejewska et al. 2004). According to latter autors that the infection level of every fish hosts of $P$. cuticola was higher in the western pool compared to the eastern one. Various degrees of fish infection with digeneans found at different locations may help us to characterize fish populations (Wierzbicki 1971, Balling and Pfeiffer 1997, Moser and Cowen 1991). Location-dependent occurrence of $P$. cuticola proved that interchange between groups of fish from the western and eastern pools of Oświn Lake is limited (Mierzejewska et al. 2004).

In the 1950s two genera of fish eyeflukesTylodelphys and Diplostomum - appeared commonly in fishes of Oświn Lake (Grabda and Grabda unpublished). The present paper provides a comparative analysis of the fish infection with eyeflukes and supplements the previous study.

Piscivorous birds-Podicipidae for Tylodelphys, Laridae and Mergidae for Diplostomum species-acts as the final host. Lymnaeid snails-mainly Lymnaea ovata and $L$. auricularia serve as the first intermediate host of both genera, while cercariae infect a variety of fish species (Niewiadomska 2003).

\section{MATERIALS AND METHODS}

Throughout 2 years (1998 and 1999), a total of 1091 fish belonging to 8 dominant species was examined: northern pike, Esox lucius L.; roach, Rutilus rutilus (L.); rudd, Scardinius erythrophthalmus (L.); tench, Tinca tinca (L.), white bream, Blicca bjoerkna (L.); carp bream, Abramis brama (L.); crucian carp, Carassius carassius (L.); and European perch, Perca fluviatilis L.

The fish were caught with gill-nets (mesh $30 \times 30 \mathrm{~mm}$ ) in the eastern and western basins, four times per year (in May, July, August, and October). Specimens examined had a broad range of length (Table 1). The lens and vitreous humour of freshly caught and killed fish were examined under a dissecting microscope in search for eyeflukes.

The prevalence and intensity of infection (range and mean number of parasites per an infected fish) were calculated following Margolis et al. (1982). Non-parametric statistics were used to find differences in the infection of fish with eyeflukes: the Kruskal-Wallis $H$-test to compare the different sampling periods and the Mann-Whitney $U$-test to compare sampling sites. Differences in the body length of fish examined in individual parts of the lake were estimated by $U$-test. To find the relationship between the fish standard length (SL) and relative number of parasites the Pearson's correlation coefficient was calculated.

\section{RESULTS}

Metacercariae inhabiting the lenses of the fish examined (exceptionally detected in the vitreous humour) were recognized as representatives of the genus Diplostomum (cf. Niewiadomska 2003). Due to the difficulties with the species identification within this genus (Niewiadomska 1996), only the generic name is used in this paper. Metacercariae of the genus Tylodelphys from the vitreous humour were identified as Tylodelphys clavata (cf. Niewiadomska 2003).

Metacercariae of Diplostomum spp. appeared in all fish species, abundantly in carp bream, white bream, roach, and rudd (Table 2). Depending on the sampling period, the mean intensity of infection of roach varied from 8.2 (in the west-

Comparison of the standard length (SL) of fish sampled in the eastern (E)

Table 1 and western (W) part of Oświn Lake; $U$, Mann-Whitney statistics

\begin{tabular}{lcccc}
\hline \multicolumn{1}{c}{ Fish species } & SL $[\mathrm{cm}](\boldsymbol{E})$ & SL $[\mathrm{cm}](\boldsymbol{W})$ & $U$ & $P$ \\
\hline Northern pike & $51.17 \pm 11.06(28.5-88.0)$ & $50.17 \pm 11.56(29.0-69.0)$ & 1945.5 & $>0.05$ \\
Roach & $15.75 \pm 3.52(11.0-25.5)$ & $16.87 \pm 3.78(11.5-24.5)$ & 2112.5 & $>0.05$ \\
Rudd & $18.71 \pm 4.20(11.0-26.0)$ & $19.85 \pm 3.31(12.0-25.0)$ & 1886.0 & $>0.05$ \\
Tench & $29.27 \pm 4.29(22.5-41.0)$ & $28.86 \pm 3.07(23.0-34.5)$ & 1864.5 & $>0.05$ \\
White bream & $14.29 \pm 3.18(10.5-21.5)$ & $15.19 \pm 3.22(9.5-21.5)$ & 1706.0 & $>0.05$ \\
Carp bream & $23.44 \pm 3.52(18.0-33.0)$ & $21.77 \pm 4.37(9.0-34.0)$ & 2568.5 & $<0.05$ \\
Crucian carp & $20.17 \pm 4.84(11.5-41.0)$ & $21.99 \pm 4.60(9.0-30.0)$ & 930.5 & $<0.05$ \\
European perch & $19.56 \pm 5.68(11.5-35.5)$ & $19.54 \pm 4.5(11.5-31.5)$ & 2986.0 & $>0.05$ \\
\hline
\end{tabular}


Table 2

Comparison of the fish infection with Diplostomum spp. in the eastern (E) and western (W) part of Oświn Lake

\begin{tabular}{lccc}
\hline \multirow{2}{*}{ Fish species } & Prevalence [\%] & \multicolumn{2}{c}{ Intensity of infection } \\
\cline { 3 - 4 } & E / W & Mean E / W & Range E / W \\
\hline Northern pike & $19.4 / 22.2$ & $1.2 / 1.2$ & $1-2 / 1-2$ \\
Roach & $95.4 / 63.7$ & $15.3 / 13.5$ & $1-53 / 1-73$ \\
Rudd & $67.1 / 45.6$ & $3.2 / 2.8$ & $1-32 / 1-11$ \\
Tench & $1.5 / 1.8$ & $2 / 1$ & $2 / 1$ \\
White bream & $100.0 / 90.0$ & $20.3 / 19.2$ & $1-47 / 1-84$ \\
Carp bream & $98.8 / 97.6$ & $23.5 / 25.5$ & $1-67 / 1-132$ \\
Crucian carp & $12.1 / 22.5$ & $1.5 / 1.4$ & $1-3 / 1-3$ \\
European perch & $20.3 / 9.3$ & $1.4 / 1.5$ & $1-3 / 1-4$ \\
\hline
\end{tabular}

Comparison of the fish infection with Tylodelphys clavata in the eastern (E) and western (W) part of Oświn Lake

\begin{tabular}{lccc}
\hline \multirow{2}{*}{ Fish species } & Prevalence [\%] & \multicolumn{2}{c}{ Intensity of infection } \\
\cline { 3 - 4 } & $\mathrm{E} / \mathrm{W}$ & Mean E / W & Range E / W \\
\hline Northern pike & $3.2 /-$ & $1.0 /-$ & $1-1 /-$ \\
Roach & $23.1 / 17.7$ & $3.9 / 3.4$ & $1-10 / 1-10$ \\
Rudd & $-/ 3.5$ & $-/ 12.5$ & $-/ 12-13$ \\
Tench & $-/-$ & $-/-$ & $-/-$ \\
White bream & $3.4 / 1.4$ & $3 / 2$ & $1-5 / 2$ \\
Carp bream & $-/ 2.4$ & $-/ 1.5$ & $-/ 1-2$ \\
Crucian carp & $-/-$ & $-/-$ & $-/-$ \\
European perch & $3.8 / 2.3$ & $2 / 3$ & $1-4 / 1-5$ \\
\hline
\end{tabular}

ern pool in October 1998 and May 1999) to 23.1 parasites per an infected fish (in the western pool in July 1998). The prevalence values were high in all samples, with the lowest value of $62.5 \%$ observed in the western pool in May 1999) (Fig. 1). The mean intensity of infection of rudd varied from 1 (in the western pool in October 1998) to 11.7 parasites per fish (in the eastern pool in October 1998) with the associated prevalence between 10 and $85.7 \%$ (Fig. 1). The mean intensity of infection of white bream ranged from 8.6 (in the western pool in May 1999) to 38.0 parasites per fish (in the eastern pool in May 1998), with the prevalence from 50 to $100 \%$ in individual seasons (Fig. 1) (lack of white bream from the eastern pool in the samples collected in August 1998 and October 1998). Mean intensity of infection of carp bream reached the values between 6.1 (in the eastern pool in October 1999) and 49 parasites per fish (in the western pool in October 1998) with the prevalence of 90-100\%.

Rudd and white bream in the eastern pool were significantly more infected with the Diplostomum spp. compared to the fish from the western pool ( $U$-test statistics at $P<0.05$ ) (Fig. 1). In accordance with the $H$-test results, the infection of roach, rudd, white bream and carp bream was season-dependent (Fig. 1). The relative number of metacercariae did not correlate with the fish standard length (SL). Pearson's correlation coefficient (r) reached 0.1 in roach, 0.08 in rudd, -0.17 in white bream, and -0.03 in carp bream, at $P>0.05$ in every fish.

Metacercariae of Tylodelphys clavata occurred in six fish species (of the eight examined), most of which were
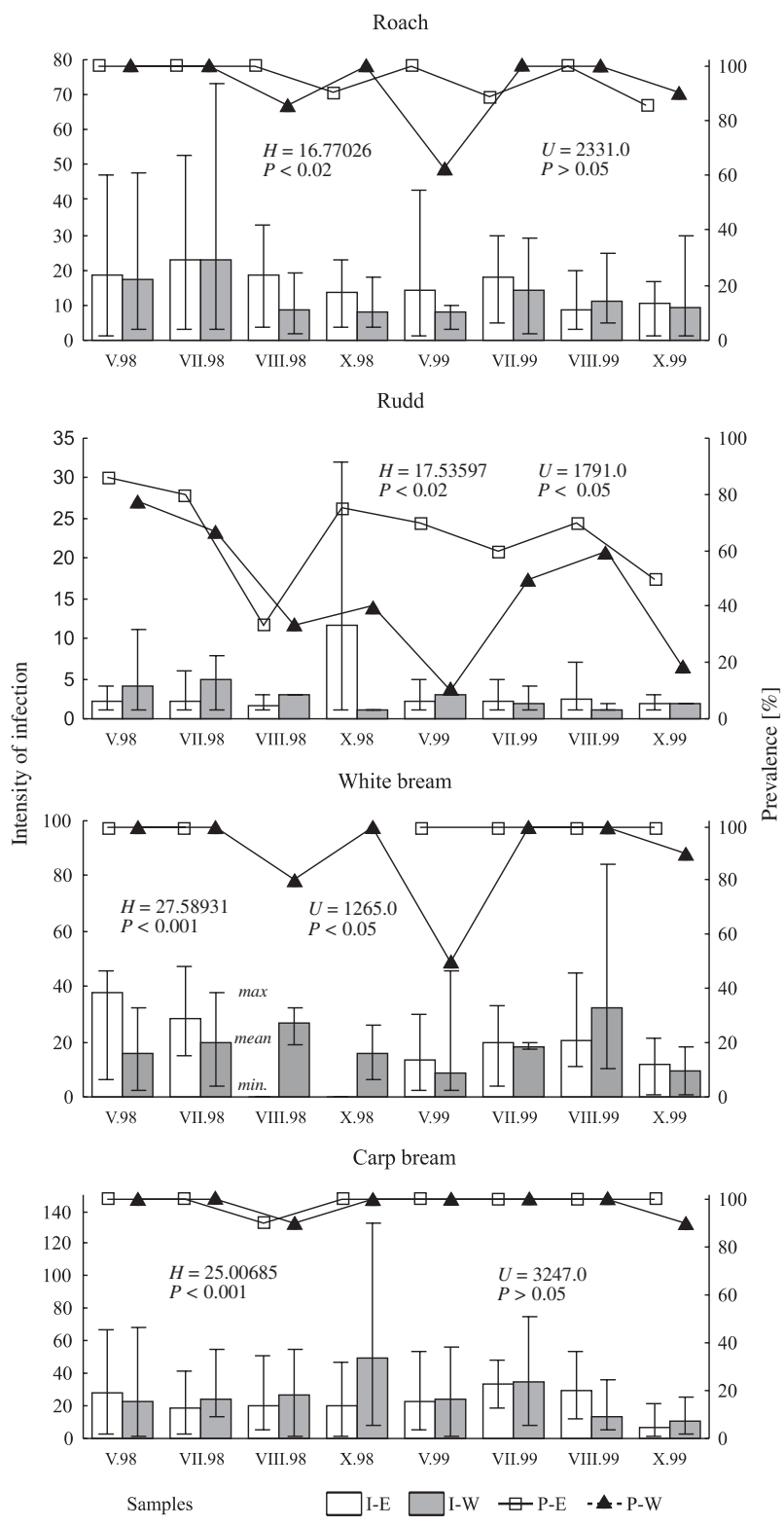

Fig. 1. Prevalence (P) and intensity of infection (I) of fish with Diplostomum sp. in samples from eastern (E) and western (W) part of Oświn Lake; $H$, Kruskal-Wallis statistic for sea sonal differences; $U$, Mann-Whitney statistic for location differences

sporadically infected, except roach, in which the total prevalence exceeded $20 \%$ (Table 3 ). The mean intensity of infection of roach in seasons varied from 0 to 10 parasites per fish at the prevalence from 0 to $57.1 \%$ (Fig. 2). The infection was not location-dependent ( $U$-test statistics at $P>0.05)$ but differed significantly in the sampling time periods $(H$-test statistics at $P<0.05)$ (Fig. 2). The relative number of metacercariae did not correlate with the fish standard length (SL); $\mathrm{r}=-0.28$ at $P>0.05$.

\section{DISCUSSION}

Metacercariae of Diplostomum spp., the parasite of Laridae and Mergidae (cf. Niewiadomska 2003), occurred in all fish species. Carp bream, white bream, roach, and rudd-the fish inhabiting the littoral and bentho-pelagic 


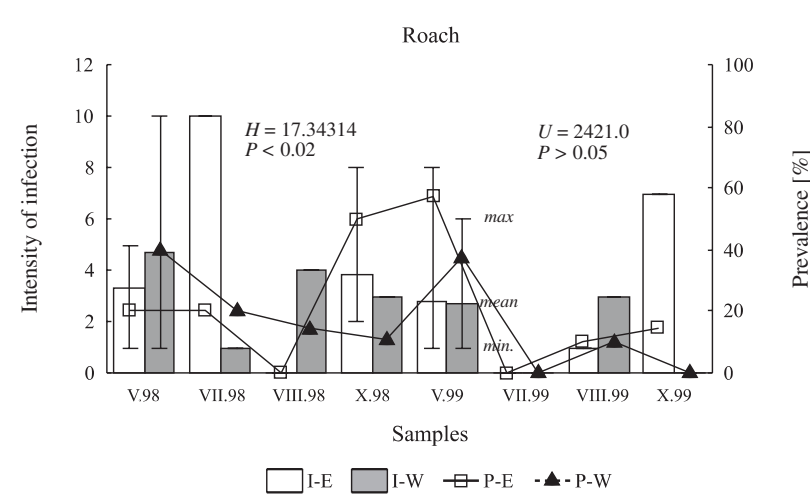

Fig. 2. Prevalence (P) and Intensity of infection (I) of roach with Tylodelphys clavata in samples from eastern (E) and western (W) part of Oświn Lake; $H$, Kruskal-Wallis statistic for seasonal differences; $U$, Mann-Whitney statistic for location differences

zone-were predictably (Holloway and Leno 1983) more infected than the other fish species examined. Compared to other reservoirs, the infection of carp bream and roach in Oświn Lake with Diplostomum spp. was relatively high, higher than in the Włocławski dam reservoir (Waluga and Własow 1988), in Tajty Lake (Kozicka 1953), in Drużno Lake (Kozicka 1958), where bird sanctuaries are also established, or in Lake Miedwie (Sobecka and Piasecki 2002). Higher intensity of infection of roach and carp bream with Diplostomum spp. was detected in the Vistula Lagoon (Rolbiecki 2003). Compared to the data from 1950s the numbers of Diplostomum spp. were higher in the presently reported study. It could be related to the increased area of the lake (from 360 to 890 ha) after the dam construction in 1993 (Wiśniewski unpublished). As Karvonen et al. (2003) suggests the fish may become more exposed to infection with the cercariae in larger volumes of water. It raises some concern as to the pathological effect of the parasite. Cataracts may possibly play a great role in causing the harmful effects on fish by reducing its vision. Such pathological effect is expected at the intensity of infection exceeding 20 metacercariae per fish (Karvonen et al. 2004). In Oświn Lake the infection intensity exceeded 50 metacercariae per fish in carp bream, white bream, and roach (Fig. 1). Therefore is is possible that the inferior growth rate of some age groups of carp bream in Oświn Lake (Chybowski et al. unpublished) was associated with diplostomid infection.

Tylodelphys clavata, the parasite linked by its live cycle with grebes (Podicipidae) occured in six out of the eight fish species examined. The prevalence ranged from 17.7 to $23.1 \%$ in roach, while in the other fish it did not exceed a few percent (Table 3). According to Grabda and Grabda (unpublished) the metacercariae from the genus Tylodelphys detected in fish eyes (both lenses and vitreous humour were examined) appeared in mass numbers in perch, were numerous in roach and rudd, and less abundant in carp bream, pike, and white bream. In the present study, the infection intensity of perch with $T$. clavata did not reach 5 metacercariae per fish, at a low prevalence (from 2.3 to $3.8 \%$ ) (Table 3 ). Roach and rudd were not severely infected either (the maximum intensity of infection reached 10 and 13 parasites per fish, respectively). The other fish species were sporadically infected (Table 3).

Decreasing numbers of grebes in the Seven Islands reserve might have caused the limitation of T. clavata population. The crested grebes, Podiceps cristatus, until recently the species breeding commonly in that area, was seen rather sporadically in 1999, with very few couples being observed and nesting not confirmed (Sikora et al. unpublished). Some dramatic changes in the environment such as the rapid water level decrease, intoxication with chemical fertilizers, disappearance of macrophyte vegetation (Bryliński et al. unpublished), had adverse effect on the living conditions of grebes at the reserve. On the other hand, from year to year the fluctuation of the parasite abundance (six-fold decrease) could be observed (Sobecka and Piasecki 2002), probably due to the short live span of T. clavata.

The rudd and white bream in the eastern part of the lake were considerably more infected with Diplostomum spp. than the fish in the western part. The infection of roach and carp bream with Diplostomum spp. and infection of roach with $T$. clavata did not differ between two parts of the lake (Figs. 1, 2).

Study on Posthodiplostomum cuticola at Oświn Lakepresented in the part I of this series (Mierzejewska et al. 2004) - indicated that the infection level of every fish hosts in the western pool was higher then in the eastern one. Possibly, because of the different distribution of planorbid snails (or infected specimens only) within the pools studied. The lack of data on molluscs in the reservoir makes verification of this hypothesis impossible. Location-dependent occurrence of parasite proved that interchange between groups of fish from the western and eastern pools of the lake is limited (Mierzejewska et al. 2004).

If lymnaeid snails (intermediate host of Diplostomum spp.) prevailed in the eastern pool-the question is - why the differences were only detected in rudd and white bream? The infection of roach and carp bream - the main hosts of the parasite-was comparable in both parts of Oświn Lake. Explanation is probably hidden in differences in ecology of those fishes.

Results of this study indicate that eyeflukes as well as the $P$. cuticola were sensitive indicators which reflected the environmental pressure (spatial differences in ecological conditions and long term alterations).

The intensity of infection with Diplostomum spp. as well as with $T$. clavata did not depend on the fish size; the relative number of parasites did not correlate with fish standard length (SL). Therefore, there is no evidence that those eyeflukes could accumulate in the host organism. In the case of T. clavata, it is natural because their life span is less than a year (Niewiadomska 1972). In contrast, the metacercariae of Diplostomum sp. could live several years and accumulate in a fish body. In perch, this kind of accumulation was detected in the case of Diplostomum gasterostei (Kennedy and Burrough 1977).

Significant influence of the sampling period on the infection of roach, rudd, white bream and carp bream with Diplostomum spp. was statistically confirmed. However, it 
cannot be stated that the differences in the infection rate were of a seasonal character because the indices did not increase in every hosts and in both parts of the lake simultaneously (Figs. 1, 2). The cyclic changes in the number of Diplostomum spp. throughout the year could not be observed probably because of the longevity of the parasite. Seasonality in the occurrence of $T$. clavata eyeflukes was also undetectable (Fig. 2), despite their shorter life span.

\section{ANCKNOWLEDGMENTS}

This study was supported by the research grant No. 080302.0205 from the University of Warmia and Mazury in Olsztyn.

\section{REFERENCES}

Balling T.E., Pfeiffer W., 1997. Location-dependent infection of fish parasites in Lake Constance. Journal of Fish Biology 51: 1025-1032.

Halmetoja A., Valtonen E.T., Koskenniemi E., 2000. Perch (Perca fluviatilis L.) parasites reflect ecosystem conditions: a comparison of a natural lake and two acidic reservoirs in Finland. International Journal for Parasitology 30: 1437-1444.

Holloway Jr H.L., Leno G.H., 1983. Infection parameters of Diplostomum spathaceum in ecologically different fish. Transactions of the American Microscopical Society 102: 92.

Karvonen A., Seppälä O., Valtonen E.T., 2004. Eye flukeinduced cataract formation in fish: quantitative analysis using an ophthalmological microscope. Parasitology 129: 473-478.

Karvonen A., Paukku S., Valtonen E.T., Hudson P.J., 2003. Transmission, infectivity and survival of Diplostomum spathaceum cercariae. Parasitology 127: 217-224.

Kennedy C.R., Burrough R.J., 1977. The population biology of two species of eyeflukes, Diplostomum gasterostei and Tylodelphys clavata, in perch. Journal of Fish Biology 11: 619-633.

Kozicka J., 1953. Pasożyty ryb w jeziorze Tajty. [Parasites of fish in Tajty Lake.] Roczniki Nauk Rolniczych D 67: 171-186. (In Polish.)

Kozicka J., 1958. Diseases of fishes of Drużno Lake. Parasitofauna of the biocenosis of Drużno Lake-Part VII. Acta Parasitologica Polonica 6: 393-432.

Kozicka J., 1963. Attempt of fishery-parasitologic estimation of the lakes of Węgorzewo Establishment. Acta Parasitologica Polonica 11: 113-131.

Margolis L., Esch G.W., Holmes J.C., Kuris A.M., Schad G.A., 1982. The use of ecological terms in parasitology (report of an ad hoc committee of the American Society of Parasitologists). International Journal for Parasitology 68: 131-133.

Mierzejewska K., Własow T., Kapusta A., Szymańczyk K., 2004. Fish digeneans from the Seven Islands ornithological reserve at Oświn Lake, Poland. Part I. Posthodiplostomum cuticola von Nordmann, 1832. Acta Ichthyologica et Piscatoria 34: 73-84.

Moser M., Cowen R.K., 1991. The effect of periodic eutrophication on parasitism and stock identification of Trematomus bernacchii (Pisces: Nototheniidae) in McMurdo Sound, Antarctica. Journal of Parasitology 77: 551-556.

Niewiadomska K., 1972. Problemy współzależności ewolucji Digenea i ich żywicieli. [Problems of interdependence connections of Digenea and their hosts evolution.] Wiadomości Parazytologiczne 18: 359-371. (In Polish.)

Niewiadomska K., 1996. The genus Diplostomum — taxonomy, morphology and biology. Acta Parasitologica 41: 55-56.

Niewiadomska K., 2003. Pasożyty ryb Polski (klucze do oznaczania). Przywry - Digenea. [The parasites of Polish fish (key to species determination). The flukes-Digenea.] PTP, Warszawa. (In Polish.)

Rolbiecki L., 2003. Diversity of the parasite fauna of cyprinid (Cyprinidae) and percid (Percidae) fishes in the Vistula Lagoon, Poland. Wiadomości Parazytologiczne 49: $125-164$.

Sobecka E., Piasecki W., 2002. Parasite fauna of selected fish species of Lake Miedwie. Wiadomości Parazytologiczne 48 (2): 207-215.

Valtonen E.T., Gibson D.I., 1997. Aspects of the biology of diplostomid matacercarial (Digenea) populations occurring in fishes in different localities of Northern Finland. Annual Zoology Fennici 34: 47-59.

Valtonen E.T., Holmes J.C., Aronen J., Rautalahti I., 2003. Parasite communities as indicators of recovery from pollution: parasites of roach (Rutilus rutilus) and perch (Perca fluviatilis) in Central Finland. Parasitology 127: 217-224.

Waluga D., Własow T., 1988. Występowanie pasożytów u leszcza (Abramis brama L.) i płoci (Rutilus rutilus L.) we Włocławskim Zbiorniku Zaporowym na rzece Wiśle. [Parasites of carp bream (Abramis brama L.) and roach (Rutilus rutilus L.) in the Włocławski Dam Reservoir at the Vistula River.] Wiadomości Parazytologiczne 34 (1): 65-75. (In Polish.)

Wierzbicki K., 1971. The effect of ecological conditions on the parasite fauna of perch Perca fluviatilis L. in Lake Dargin. Ekologia Polska 19: 73-86.

Własow T., Zmysłowska I., Lewandowska D., Mierzejewska K., Idzikowski R., Ziomek E., 2003. Bacteria and parasites on the gills of pike Esox lucius L. and tench Tinca tinca (L.) as indices of the trophic level of Oświn Lake (northeastern Poland). Archives of Polish Fisheries 11: 225-235.

Received: 30 November 2004 Accepted: 22 December 2004 